\title{
When teachers are seen as kind: An automatic response experiment on Filipino children's perception of their early grade teachers
}

Rungduin, Teresita

Educational Policy Research and Development Center, Philippine Normal University-Manila, Philippines (rungduin.tt@pnu.edu.ph)

Acopio, John Ray B. $\triangle$

Center for Guidance and Counseling, Mapua University-Makati, Philippines (jrbacopio@mapua.edu.ph)

Rungduin, Darwin C.

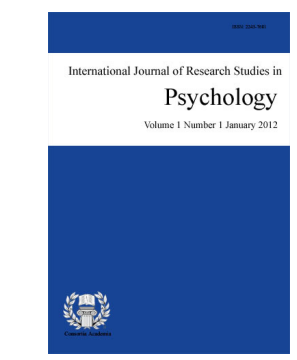

ISSN: $2243-7681$ Online ISSN: 2243-769X

OPEN ACCESS

College of Liberal Arts, Colegio de San Juan de Letran-Manila, Philippines (darwin.rungduin@letran.edu.ph)

Madrid, Mirasol S.

High School Department, Assumption College-Makati, Philippines (madridmirasols@gmail.com)

Cruz, Nathalie A.

Guidance Department, Colegio San Agustin-Makati, Philippines (nathaliaawayancruz@gmail.com)

Sangalang, Kristine Joy P.

Human Resource Department, Macquarie Offshores Services, Philippines (Kristinejs1@gmail.com)

Sulit, John Patrick C.

Guidance Department, Claret School of Quezon City, Philippines (jpcsulit@gmail.com)

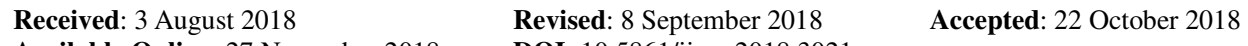

Available Online: 27 November 2018 DOI: $10.5861 /$ ijrsp.2018.3021

\section{Abstract}

Children's perception about their teachers has been widely addressed utilizing student evaluation of teacher's performance. However, there is with regard to how children perceive their teachers based on the warmth - competent dimensions following Fiske's Stereotype Content Modeling Theory (2006). Using a within-subject randomized block design through the process of Psychopy, a sample of 80 kindergarten to Grade 3 Filipino students were presented with word-stimuli describing their teachers as either warm or competent. The word-stimuli tasks revealed how these learners regularly construct and use categorical representations to simplify how they make sense of other people. Paired sample t-test analysis supports Fiske's notion that warmth is primarily perceived, while competence takes a secondary role. Results suggest that students perceive the warmth dimension as integral in social judgment about teachers and thus affects stereotypical ideas of teachers needing to be more nurturing. The results show in-service teachers how they are stereotyped by their young students and highlights characteristics that contribute to the teaching-learning process. Thus, this study supports the claim that cognition about teachers and how they should relate with their students usually form a psychological process of inducing positive emotions and relationships towards learning, lending a classroom atmosphere that promotes a healthy student-teacher relationship which consequently reinforces students' learning.

Keywords: competent teachers; Stereotype Content Model (SCM); universal social cognition; warm teachers; Psychopy 


\section{When teachers are seen as kind: An automatic response experiment on Filipino children's perception of their early grade teachers}

\section{Introduction}

Recognition of children's perception on their teachers can help researchers identify the positive practices that can be implemented and reinforced in the classroom. The first important non-family adults that children develop a relationship with are educators, particularly teachers (Dobbs \& Arnold, 2009). The attitudes and beliefs of a teacher may be influential in shaping a child's belief system; as children are keen observing both verbal and non-verbal cues from the teacher, it is but inevitable that they will imitate the teacher's words and behaviors. And this can be apparent even later in life. What transpires inside the classroom dictates the norms observed while in class. This inevitably makes children's early life experiences fundamentally predisposed to be highly affected by the learning environment - through developing skills and acquiring social knowledge while inside the classroom. Thus, it supports the assumption that preschool teachers (Kemple, 2004) in a student-teacher relationship (Baker, Terry, Bridger, \& Windsor, 1997) involve in an essential role to reinforce the social development of children (Kemple, 2004), increased classroom participation (Skinner, Furrer, Marchand, \& Kindermann, 2008), and overall school and behavioral adjustment (Baker et al., 1997).

Some landmark studies to strengthen the claims that children's experiences from their preschool years can definitely shape the quality of the relationship between teachers and children (Buyse, Verschueren, \& Doumen, 2011). Boseovski (2010) observed that children seem to perceive different aspects of life through a more optimistic outlook. Denham (1986) theorized that in order for children to understand others' feelings, children show non-egocentric and inferential abilities, as well as greater cognitive perspective-taking abilities. On the other hand, Lalonde and Chandler (2002) have postulated that children's theory of mind develops in two stages. First, children between 3 to 5 years old can pass false-belief tasks through the rule "seeing is knowing." Second, children around 6 years old begin to understand that knowledge and beliefs may come from different activities through interpretation. Since this period of childhood development is crucial for formation of habits (Barazza, 2001), the way teachers present themselves in a class would somehow influence their pupils' perception of who they are, and consequently affect their treatment with each other-suggesting a need to develop new measures for children's social information processing to further understand how children try to understand and assess their surroundings (Lailble, Carlo, McGinley, \& Augustine, 2013) most especially teachers.

In Philippine culture, whether inside or outside of the classroom, educators are perceived as caring agents (de Guzman, Uy, Sy, Torres, Tancioco, \& Hernandez, 2008). It is through setting examples or modelling that teachers impart good values to their pupils (de Guzman et al., 2008). Beyond their warm and nurturing qualities, teachers are expected to be skilled and masterful in their profession. This paper carefully gauged if teachers are largely perceived as either warm or competent anchored on the Fiske's Stereotype Content Model (SCM). Recent theories on universal social cognition suggest that by association, competence traits are linked to intelligence, skill, and efficacy; on the other hand, characteristics like empathy, friendliness, kindness, and trustworthiness are more likely to be attributed to warmth traits (Cuddy, Glick, \& Beninger, 2011). These two universal dimensions of social cognition characterize the fundamental dimensions of person perception (Cuddy et al., 2011), which lead to the path of significantly encouraging educational institutions to cultivate the warmth-related traits of pre-service school teachers or concentrate on preparing them to be more skilled on both strategies and contents. As indispensable as it sounds, teachers' ability to be masterful in teaching and their innate quality to be more emphatic and caring to their pupils may or may not affect learners' potential to be exemplary students. These points are indispensable to the teaching-learning process in light of the fact that if educators are seen to be high or less in warmth and competence dimensions, students are most likely to perform in ways that may or may not boost their learning potentials. 
Despite the efforts of some schools in the Philippines to provide sufficient trainings for pre-service and in-service teachers on competence and warmth, this effort is inadequate to provide valuable data that can further address issues concerning automatic processes among learners when it comes to their primary facilitator of knowledge. With the ultimate goal of training competent and warm teachers-which Philippine educational system places high regards on through teacher preparation and training among pre-service and in-service school teachers-this study calls for the generation of baseline data that identify student's social cognition of teachers. This current study proposes that it is probable that students' cognition about their teachers and how these educators relate to their students can induce positive emotions and relationship toward learning.

\subsection{Universal Social Cognition}

Various studies have recognized the social nature of cognition and how social environment impacts an individual (Akkerman \& Meijer, 2011). Others with whom an individual collaborates are viewed as critical to the self since they inspire them to go about, and in addition, grow advance in a specific direction (Akkerman \& Meijer, 2011). Similar to the classroom setup, teachers turn into the most prevailing and compelling entity that impacts their students' perception of who they are, and therefore influences how they treat each other. Teaching, as the noble profession, does not just simply include transmission of learning but rather, more notably, a longstanding and dedicated pledge to human changes (de Guzman et al., 2008). Thus, teachers must strive to be more mindful of their words and actions - as all these can affect the way students perceive them. Recent studies about this subject have shown significant findings that different educational institutions can learn from.

The organization of mental ideas and activities studied by Stereotype Content Model (SCM) concentrated on diagnosticity of warmth and competence dimensions. This means that individuals who became the subjects of investigation often observe others' behaviors and attempt to form an impression about their personality and behaviors. The warmth dimension speaks on how friendly, dependable, kind, empathic these people are seen (Cuddy et al., 2011; Aktan, 2013), while competence dimension reflects how skillful, confident and efficient individuals are depicted (Aktan, 2013) - both of these are identified as the key measurements of social cognition. For instance, Ybarra, Chan, and Park (2001) investigated older and younger adults' sensitivity to character information from morality (warmth) domain and the competence domain. They found that with no age restrictions, people recognized words faster that describe warmth-related trait than competence-related trait in lexical decision tasks. Almost similar results were also found by Willis and Todorov (2006) in drawing trait inferences from the facial appearance of other people. They have discovered that social perceiver inferred trustworthiness (akin to warmth) significantly faster than competence after an exposure time of 100ms. These studies of Ybarra et al. (2001) and Willis and Todorov (2006) further strengthened what Fiske, Cuddy, and Glick (2006) stated that individuals are more sensitive to warmth than competence stimuli. Fiske et al. (2006) noted that people who are inclined to lean on the warmth dimension must adhere to small range of moral-sociable behavior, while people who are disposed to be high on competence dimension might behave competently most of the time and do not discount their general competence even if few incompetent behaviors are manifested.

This claim made by Fiske et al. (2006) generated a strong conceptual argument using experimentation on how students view their teachers addressing concerns on teacher preparation and training. Significant to this role is the quality of teaching that educators offer to facilitate necessary pedagogical content knowledge and skills. Assumed that students must learn both theoretical knowledge and practical skills, good interpersonal skills that teachers employ in their classrooms are also critical. Thus, this study made an attempt to categorize how young learners perceive their teachers using textual description on a computer-based generated Psychopy. This will address issues concerning cognitions using brain-based tools to provide evidences in relation to the differences between executive cognitive functioning. In this study, as Fiske, Cuddy, Glick, and Xu (2002) recognized consistent competence and warmth evaluation toward particular point of reference, the fundamental concentration will be on teachers and how they are perceived by their students.

\subsection{Warmth as Primary, Competence as Secondary}


Fiske et al. (2006) argues that although warmth and competence dimensions emerge consistently, there are evidences that warmth is judged before competence. Interestingly, studies on the primacy of warmth judgment provided information that as one perceives someone to be warm, succeeding judgments focus on disconfirming it. On the other hand, competence as a secondary judgment perception is related to how the person sees the other as competent-that is if the person is believed to be competent, instances, where incompetence is displayed may be disregarded. It is the other way around among individuals who were perceived to be incompetent, another person's judgment continues to prove that the person is actually incompetent. For this study, the students might assess the teacher according to his/her competence or warmth. These can be employed to foresee the conceivable situation in the classroom, perhaps their first encounter with their teachers. As a result, these prospects can lead to stereotypes as their assessment to their teachers. These points are integral to the teaching-learning process because if teachers are perceived to be less warm and less competent, students are most likely to perform in ways that may not maximize their learning potentials.

\subsection{The Problem and the Hypotheses}

Due to its impending implication towards understanding Fiske's universal social cognition spectrum using the Stereotype Content Model (SCM) in teacher preparation and training, the present study calls for the exploration of social cognition (either warmth or competence) of the participants to their teachers. The relatively shorter time response in the experiment created in Psychopy provides inferences on the participants' thought-processing when it comes to what they believe to be socially appropriate responses and may affect how they view their teachers' characters. It is strongly posited by the current study that:

H1: The participants would perceive their teachers as positive-warm than positive-competent as manifested in a shorter response rate.

$>$ H2: The participants would perceive their teachers as negative-warm than negative-competent as manifested in a shorter response rate.

\section{Methods}

\subsection{Sample and Procedures}

Through stratified random sampling, eighty (80) young students across K-3 (kindergarten, grades 1, 2 and 3) levels enrolled in three (3) public schools were selected to take part in the experiment. After which, random assignment was conducted to ensure that all students had equal chances of being selected. The final selection was comprised of 20 students each level. There were 33 males (41.30\%) and 47 females (58.8\%) with age ranging from 5 to 9 years old. They were the best choice for this study because at this stage of their lives, their minds still undergo developmental changes intellectually and socially (Piaget, 1969 as cited by Barraza, 2001; Vygotzky, 1978 as cited by Barraza, 2001) thus, the best time to prime the students of what a teacher should possess or not which eventually affects stereotypical ideas of teachers.

Agreement among the researchers, school administrators, guardians of the students was secured before the facilitation of the experiment. Proper parents' consent was sought and the procedures, benefits, and risk to the participants of the study were thoroughly explained. It is assured that participants' participation was voluntary. Experiments were conducted in the academic year 2016 to 2017. Students attended four sessions arranged by their schools. Orientation about the experiment and a trial of how the experiment would go about was performed during the first session. Experimentation proper was scheduled on the second session while explanation of the results was conducted during the third session. Lastly, debriefing and group dynamic activity was implemented during the fourth session.

The experiment utilized the within-subject randomized design wherein all participants were exposed more 
than once to the different sets of words and consequently, the researchers analyzed the data gathered. A pre-survey of trait-characteristics attributed to teachers by students was devised prior to experimentation. The trait-listing was categorized between warmth-related or competence-related categories. The final list was used for the Psychopy programming. Psychopy is a free computer software used in designing social cognition experiments where stimulus words are encoded with the response time measured in milliseconds (Peirce, 2009). The experiment consisted of four treatment levels: (1) Positive Competence-Neutral (PCNe) was paired with (2) Positive Warmth-Neutral (PWNe) and (3) Negative Competence-Neutral (NCNe) was paired with (4) Negative Warmth-Neutral (NWNe) traits using Psychopy.

\subsection{Measures}

Social Cognition Tasks - The social cognition tasks included 20-word list coming from a pre-survey of the traits students perceive of their teachers to 100 students. Each word (either negative warmth/competence or positive warmth/competence) is paired with a neutral word serving as a manipulation check. Items were constructed in Filipino due to the age range of the participants. Words given in English from the survey were provided with Filipino translations and were subject to external validation. Content wise, experts in psychology agreed that words given from the pre-survey measured the universal social cognition's warmth/competence dimensions. Language wise, an expert in back translation ensured the accuracy of the exact meaning of the translation in the Filipino language. After which, the final list of words was entered into a computer program, Psychopy, which was checked by an Information and Technology (IT) specialist who has knowledge on how to operate the said program.

With the presence of the researchers as experimenters, and teachers together with a psychologist to run the experiments, the participants were asked to look at the computer and choose between two-trait pairs which were chosen word per item automatically saved after every trial. Each set of word has a preset response. Each participant has an experimenter-partner for guidance and monitoring. The social cognition tasks were designed with practice stimuli of two-trait pairs to address familiarity with the process. Prior to these social cognition tasks, a manipulation check was administered to measure the students' understanding of the experimental process.

\subsection{Data Analysis}

To determine the differences of warmth and competence spectrum of Fiske's social cognition through the created experiment in Psychopy, a paired sample $t$-test performed in SPSS 17.0 was utilized. Means and standard deviations of two conditions under Pair 1 (positive competence-neutral vs. positive warmth-neutral) and Pair 2 (negative competence-neutral vs. negative warmth-neutral) were then analyzed. Prior to conducting a paired sample $t$-test, estimation of correlation using person's correlation between variables in Pair 1 and Pair 2 was conducted, suggesting that the paired sample $t$-test is best to use. Essential to the assessment of the variables in the study are mean scores and standard deviations.

\section{Results and Discussions}

Hypothesizing that Pair 1 (positive competence-neutral vs. positive warmth-neutral) and Pair 2 (negative competence-neutral vs. negative warmth-neutral) means were equal, a paired sample $t$-test was utilized. Investigated prior to analysis was the assumption of normal distributed data (in milliseconds). The result showed that the assumption qualifies as satisfied basing on the estimation of the skew and kurtosis levels - which apparently was less than the maximum acceptable values for t-test. Estimation of correlation between variables in Pair 1 and Pair 2 was conducted, suggesting that the paired sample $t$-test is suitable in this case. Thus, both null hypotheses for Pair 1 and Pair 2 were rejected, allowing the results to have significant differences. 
Rungduin, T., Acopio, J. R. B., Rungduin, D. C., Madrid, M. S., Cruz, N. A., Sangalang, K. J. P., \& Sulit, J. P. C.

\section{Table 1}

Results comparing Time Responses (ms) on Teacher's Positive Competence-Positive Warmth Traits

\begin{tabular}{lcccccc}
\hline \multicolumn{1}{c}{ Teacher's Traits } & Mean & SD & $t$ & df & $r$ & $p$ \\
\hline Positive Competence-Neutral & 6.93 & 3.31 & $3.27^{*}$ & 79 & $.68^{*}$ & $.002 *$ \\
Positive Warmth-Neutral & 6.02 & 3.16 & & & & \\
\hline
\end{tabular}

Note. ${ }^{*} p<.05 ; \mathrm{N}=80$

A paired samples t-test (see table 1) was conducted to compare time (in milliseconds) responses between positive competence-neutral and positive warmth-neutral traits of teachers. There was a significant difference in the time (in milliseconds) responses for positive competence-neutral $(\mathrm{M}=6.93, \mathrm{SD}=3.13)$ and positive warmth-neutral $(\mathrm{M}=6.02, \mathrm{SD}=3.16)$ traits; $t(79)=3.37, p=.002$. These results suggest that time appears to drop an average of about 0.91 milliseconds following the response to the next set of stimuli, suggesting that the participants responded more quickly on the positive neutral-warmth than positive neutral-competence traits of their teachers. Cohen's $d$ at 46 percent is a large effect based on Cohen's (1992) estimation guidelines, suggesting that Pair 1 has the best fit of data compared to all other pairings produced.

Table 2

Results comparing Time Responses (ms) on Teacher's Negative Competence-Negative Warmth Traits

\begin{tabular}{lcccccc}
\hline \multicolumn{1}{c}{ Teacher's Traits } & Mean & SD & $t$ & df & $r$ & $p$ \\
\hline Negative Competence-Neutral & 5.27 & 2.64 & $2.36^{*}$ & 79 & $.40^{*}$ & $.021^{*}$ \\
Negative Warmth-Neutral & 5.02 & 2.13 & & & & \\
\hline Note. ${ }^{*} p<.05 ; \mathrm{N}=80$ & & & & & & \\
\hline
\end{tabular}

When negative competence-neutral trait $(M=5.72, \mathrm{SD}=2.64)$ was paired with negative warmth-neutral trait $(\mathrm{M}=5.02, \mathrm{SD}=2.13)$, a significant difference was found. These results suggest that time appears to drop an average of about 0.70 milliseconds following the response to the next set of stimuli, lending that the participants responded more quickly on the negative warmth-neutral than negative competence-neutral traits of their teachers (see table 2). The effect size in Pair 2 accounted for about 36 percent leaving 64 percent attributed to other factors. Thus, this suggests that Pair 2 has given the best fit of data.

The result of the study clearly supports Boseovski's (2010) claim that children perceive the world through a positive lens. The opportunities provided by their caregivers in making sense of their environment are internalized and thereby influence how they see others. The results significantly showed that once children start school, their social perceptions change in consonance with actual interactions with the teacher; the initial impressions of the teacher's characters are associated with their inclination toward either validations of warmth and competence. Warmth-related characteristics as discussed in early studies (Ybarra et al., 2001; Willis \& Todorov, 2006; Fiske et al., 2006) are easily recognized and are automatically processed. This process had been observed in the shorter response time with warmth-positive traits. Children automatically process caring and nurturing qualities more than competence-related characteristics. In the negative-neutral stimuli, negative-warmth was chosen over negative-competence traits. This cognitive processing had shed light to the top-of-the-mind characterization of teachers as warmth (either positive or negative). The study further supports what Fiske et al. (2006; p. 79) hypothesized that people are more sensitive to the warmth stimuli and are inclined to highlight moral-sociable behaviors.

When analyzing the response rates of warmth/competence traits and neutral traits (warmth/competence), the study posits that between a negative warmth trait stimulus and a neutral trait stimulus, children are more likely to respond quicker by choosing the neutral trait over the negative trait. This likewise holds true for negative competence trait stimulus paired with neutral trait stimulus. The cognitive processing supports Lalonde and Chandler (2002) — as children engage in various activities with their teachers, negative stimuli traits seem to be blocked off when it comes to judgment made toward their teachers. The relatively shorter time response, likewise, 
When teachers are seen as kind: An automatic response experiment on Filipino children's perception of teachers

provides inferences on children's thought-processing when it comes to what they believe to be socially appropriate responses and may affect how they view their teachers' characters.

\section{Conclusion and Recommendation}

The current study examined the relatively shorter time response of the participants towards their teachers' characteristic as either warm or competent. First, the study calls to compare the mean time differences (in milliseconds) of positive competence-neutral (PCNe) to positive warmth-neutral (PWNe) and negative competence-neutral $(\mathrm{NCNe})$ to negative warmth-neutral $(\mathrm{NWNe})$. Empirical results show that the participants quickly responded to warmth-neutral trait (positive and negative) over competence-neutral trait (positive and negative). When positive warmth traits are seen, models of these traits are more likely to be salient among children which in return may affect the development of the children's wellbeing. This solidifies the truth about the notion that teachers can play a big role in the reinforcement of children's social development (Kemple, 2004), increased participation (Skinner et al., 2008), and overall school and behavioral adjustment (Baker et al., 1997)_further strengthening the claims that children's experiences from early years in school can definitely shape the quality of the teacher-child relationship (Buyse et al., 2011). The pairings in hypotheses 1 and 2 only show that competence should be paired with warmth traits - as these are important and seminal qualities that children remember about their teachers. Young as they are, children form their schema of people who will contribute to their knowledge and character.

This study strongly supports the social cognition theory emphasizing how people form stereotypes of people they meet and interact with. In the case of the students in the early grades, warmth traits are given more importance and are remembered better than competence-related traits. Apparently, it is more important for young students when teachers are caring and kind as opposed to the educators being intelligent and are able to exhibit mastery of the lessons they handle. Aside from serving as a supplement empirical research of the past studies, the results also noted the large effect sizes including 46 percent for Pair 1 and 36 percent for Pair 2, lending almost 50 percent of each pair to be attributed to other factors. Therefore, these outcomes substantially affirm and concur to the earlier writer implications of universal social cognition to comprehend certain aspect of a child's individuality and extend the negligible literature on this research interest in the Philippine education system.

The study is useful to understanding how children in the early years perceive their teachers grounded on first impressions. The study revealed that children saw teachers positively and regard them as persons displaying care and nurturance. This is the traits expected of teachers of children based on the literature reviewed. It is also noteworthy to mention that children also perceive them negatively (low warmth), they are seen as strict and hostile. The data showing that teachers are not warm among young learners is an unexpected result and would warrant further study. The process of perceiving teachers may be sourced from the types of emotions and its intensity the students may have felt upon their first encounter. The inferences may inform practitioners on how young learners should be approached and attended to because negative traits tend to become salient and may induce an overall negative impression of school. The results, likewise, lead to developing an understanding of which emotions should be targeted upon from the students based on the teachers' traits. The results support what has been understood that if the school climate promotes a positive atmosphere, positive impressions of the school personnel (teachers) and the school community in general will be favorable. Lastly, the study contributes to the growing research of social cognition and attitude formation using teachers as the primary target person.

Although the current's research results are relevant and remarkable, the limitations it faced are quite important to be mentioned. Up to this day, universal social cognition is still a subject that needs further examination-especially studies that are based on Philippine setting. A wider sphere and dimension for exploration can still be done about social cognition among children, especially when it comes to social perceptions formed about people who they are directly communicating with on a regular basis. The study needs further validation when it comes to warmth-competence pairings and the role of more neutral traits when paired with negative-warmth or negative-competence traits. Inquiries on the development of social cognition should also be 
investigated with more student samplings and explore how these stereotypes differ as they go from one grade level to the next. It is also recommended that succeeding studies must involve a larger number of respondents as the current research only involved a fewer number of K3 pupils. Future research may also apply universal social cognition utilizing other demographic profiles such as gender and age and make comparison of each variable interest. Future research may also check what other factors contribute to young learners' perception of their teachers aside from what was mentioned by this study. Furthermore, a measure on how Filipino children process social information, particularly cognition about teachers, may also be developed to identify precisely how these children view their teachers-supporting Lailble et al.'s (2013) recommendation to develop new measures for children's social processing information. The findings of this research build a strong foundation for future research on K3 pupils, and direction for school administration.

Acknowledgement - The authors would like to extend its gratitude to the workforce behind Faculty of Behavioral and Social Sciences, Philippine Normal University-Manila, and Department of Psychology, Colegio de San Juan de Letran-Manila for their assistance in the implementation of the study.

\section{References}

Akkerman, S. F., \& Meijer, P. C. (2011). A dialogical approach to conceptualizing teacher identity. Teaching and Teacher Education, 27(2), 308-319. https://doi.org/10.1016/j.tate.2010.08.013

Aktan, T. (2013). A contextual approach to stereotype content model: Stereotype contents in context. Procedia-Social and Behavioral Sciences, 82, 440-444. https://doi.org/10.1016/j.sbspro.2013.06.290

Baker, J. A., Terry, T., Bridger, R., \& Winsor, A. (1997). School as caring communities: A relational approach to school reform. School Psychology Review, 26(4), 586-602.

Barraza, L. (2001). Perception of social and environmental problems by English and Mexican school children. Canadian Journal of Environmental Education, 6, 139-157.

Boseovski, J. J. (2010), Evidence for "rose-colored glasses": An examination of the positivity bias in young children's personality judgments. Child Development Perspectives, 4(3), 212-218. https://doi.org/10.1111/j.1750-8606.2010.00149.x

Buyse, E., Verschueren, K., \& Doumen, S. (2011), Preschoolers' attachment to mother and risk for adjustment problems in kindergarten: Can teachers make a difference? Social Development, 20, 33-50. https://doi.org/10.1111/j.1467-9507.2009.00555.x

Cuddy, A. J. C., Glick, P., \& Beninger, A. (2011). The dynamics of warmth and competence judgments, and their outcomes in organizations. Research in Organizational Behavior, 31, 73-98. https://doi.org/10.1016/jriob.2011.10.004

de Guzman A. B., Uy, M. M., Siy, E. Y., Torres, R. K. C., Tancioco, J. B. F., \& Hernandez, J. R. (2008). From teaching from the heart to teaching with a heart: Segmenting Filipino college students' views of their teachers' caring behavior and their orientations as cared-for individuals. Asia Pacific Education Review, 9(4), 487-502. https://doi.org/10.1007/BF03025665

Denham, S. (1986). Social cognition, prosocial behavior, and emotion in preschoolers: Contextual validation. Child Development, 57(1), 194-201. https://doi.org/10.1111/1467-8624.ep7251040

Cohen, J. (1992). Quantitative methods in psychology: A power primer. Psychological Bulletin, 112(1), $155-159$. https://doi.org/10.1037/0033-2909.112.1.155

Dobbs, J. \& Arnold, D. H. (2009). The relationship between preschool teacher's reports of children's behavior and their behavior towards those children. School Psychology Quarterly, 24(2), 95-105. https://doi.org/1037/10016157

Fiske, S. T., Cuddy, A. J. C, \& Glick, P. (2006). Universal dimensions of social cognition: Warmth and competence. Trends in Cognitive Sciences, 11(2), 77-83. https://doi.org/10.106/j.tics.2006.11.005

Fiske, S. T., Cuddy, A. J. ., Glick, P., \& Xu, J. (2002). A model of (often mixed) stereotype content: Competence and warmth respectively follow from perceived status and competition. Journal of Personality and Social 
When teachers are seen as kind: An automatic response experiment on Filipino children's perception of teachers Psychology, 82(6), 878-902. https://doi.org/10.1037/0022-3514.82.6.878

Kemple, M. K. (2004). Let's be friends: peer competence and social inclusion in early childhood programs. Retrieved from http://docslide.net/documents/lets-be-friends-peer-competence-and-social-inclusion-in-early-childhood-pr ograms.html

Laible, D., McGinley, M., Carlo, G., Augustine, M., \& Murphy, T. (2014). Does engaging in prosocial behavior make children see the world through rose-colored glasses? Developmental Psychology, 50(3), 872-880. https://doi.org/10.1037/a0033905

Lalonde, C. E., \& Chandler, M. J. (2002). New Ideas in Psychology, 20(2-3), 163-198. https://doi.org/10.1016/S0732-118X(02)00007-7

Peirce, J. W. (2009). Generating stimuli for neuroscience using Psychopy. Frontiers in Neuroinformatics, 2(10), 1-8. https://doi.org/10.3389/neuro.11.010.2008

Skinner, E. A., Furrer, C. J., Marchand, G., \& Kindermann, T. (2008). Engagement and disaffection in the classroom: Part of a larger motivation dynamic? Journal of Education Psychology, 100(4), 765-781. https://doi.org/10.1037/a0012840

Willis, J., \& Todorov, A. (2006). First impressions: Making up your mind after a 100ms exposure to a face, Psychological Science, 17(7), 592-598. https://doi.org/10.1111/j.1467-9280.2006.01750.x

Ybarra, O., Chan, E., \& Park, D. (2001). Young and old adults' concerns about morality and competence. Motivation and Emotion, 25(2), 85-100. https://doi.org/10.1023/A:101633908298 
Rungduin, T., Acopio, J. R. B., Rungduin, D. C., Madrid, M. S., Cruz, N. A., Sangalang, K. J. P., \& Sulit, J. P. C. 